\title{
Salt and High Blood Pressure the Two Silent Killers: A Nepalese Perspective
}

\author{
Vaidya $A^{*}$ \\ - Kathmandu Medical College \\ Corresponding: Dr. Abhinav Vaidya \\ Department of Community Medicine, Kathmandu Medical College, Duwakot, Bhaktapur, Nepal \\ Email: drabhinavaidya@gmail.com
}

\begin{abstract}
Hypertension is now a public health problem worldwide. Studies done in the past and in the recent times in Nepal indicate a rising epidemic here as well. Salt is one of the factors always associated with high blood pressure. The article attempts to review this relation, particularly in the context of Nepal. It also touches upon the controversies surrounding salt and blood pressure, and ends with recom-mendations on reducing salt in the diet.
\end{abstract}

Keywords : Hypertension, Salt intake

\section{INTRODUCTION}

One on four adults worldwide is estimated to have high blood pressure. 1 this commonly occurring type of hypertension, known as Primary or Essential hypertension, was once thought to be of self origin, meaning that it was not caused by some other agent or condition (hence the term primary or essential). However, the numerous studies worldwide have shown that it is not entirely 'causeless'. Different conditions or behaviors, called as risk factors, can make one more vulnerable than the others to develop hypertension. Some of these risk factors are non-modifiable. i.e. one cannot do much about it; for example: age, sex and family history of high blood pressure. Others are behavior or lifestyle-related: smoking, excess alcohol intake, lack of physical activity which are avoidable or modifiable. Salt is another important life-style risk factor for developing high blood pressure: 3 out of 10 cases of high blood pressure are due to excess salt intake. This article focuses on some of the issues related to salt and hypertension, particularly in relation to Nepal's context.

\section{HYPERTENSION IN NEPAL}

The first scientific hypertension survey in Nepal was done in 1981 by Dr. Mrigendra Raj Pandey and Mrigendra Samjhana Medical Trust. 2-4 The prevalence of hypertension according to the then used WHO criteria $(160 / 95 \mathrm{~mm} \mathrm{Hg})$ in the various parts of the country were as follows: $5.3 \%$ in Mountains (Jumla), 6\% in rural kathmandu (Bhadrabas), $8.1 \%$ in Terai plains (Parsauni) and $9.9 \%$ in urban Kathmandu. The trust, in collaboration with Nepal Hypertension Society, did a repeat survey in Bhadrabas in 2006 with the new cut-offs given by JNC VII $(140 / 90 \mathrm{~mm} \mathrm{Hg})$, and found the prevalence to be as high as $33.8 \%$, which is an enormous figure. To make a rational comparison between the 1981 and 2006 data, same cut-off points should be used for both the data. So when the 2006 data was re-analysed using the old criteria of 1981 i.e. $160 / 95 \mathrm{~mm} \mathrm{Hg}$, the prevalence in 2006 was calculated to be
$18 \%$. It means that hypertension had tripled (from $6 \%$ to $18 \%$ ) in the same place in a span of 25 years!

Other recent studies done in other parts of Nepal also indicate that hypertension is now a very common disease of our society. For example, a blood pressure study in Dharan town of eastern Nepal in 2004-5 found a prevalence of almost $23 \%$. 5 Similarly, PK Ghimire found a $10 \%$ prevalence of hypertension in the western Nepal town of Surkhet in 2003.6 Putting together all the available studies, it may be said that at present about one in four Nepalese adults have got high blood pressure.

\section{Salt and blood pressure}

For centuries, salt (sodium chloride) has been regarded as one of the most important items of diet for health. Salt was so important that people were actually paid in salt (hence the word 'salary'). It plays a major part in the regulation of fluids within the body. Muck of what we consume is excreted in out sweat and urine. But individuals vary in their capacity of flush salt from their bodies. It is believed that our ancestors ate far less salt (less than 1 gram per day) than we do today. Today, some peopleconsume even up to 10 times that amount. Scientists thin out genetic makeup is still designed to precess the smaller amounts of salt out consumption leads to higher incidences of heart and kidney disease, and hypertension. This was well demonstrated in the recent DASH (Dietary Approaches to Stop Hypertension) study which meticulously monitored salt intake of 412 hypertensive individuals. 7They were given varying amounts of salt in their diet. The researchers found a very significant reduction in blood pressure for those on a low salt diet. This effect of salt on blood presure was also well demonstracte in the study done by Mrigendrea Samhana medical Trust that demonstrated a 3 -fold rise of hypertension in the same locality after 25 years: high salt intake ( $>5 \mathrm{gm}$ per day) had also increased from $56 \%$ in 1982 to $90 \%$ in 2007 . furthermore, a new research showed that UK children and adolescents who ate less salt also drank fewer sugar-sweetened 
soft drinks and had significantly lower risks for obesity, later in the life. 8 Interestingly, in their article 'Modernization and children's blood pressure: On and off the tourist trail in Nepal', Tessa M. Pollard also demonstrated how modernization had led to increased blood pressure in the children loving along the Annapurna trial. 9

Not everyone's blood pressure, however, is equally sensitive to the amount of salt consumed. A World Health Organization study of more than 7,000 people aged 50 to 54 years old, called CARDIAC, found men to be more salt sensitive than women, although women who were postmenopausal did show increased blood pressure, suggesting a tendency for salt sensitivity to increase at menopause. The INTERSALT study of more than 10,000 people in 52 different study centers showed young adults were generally less sensitive. 10 In Nepal's context, Dr. Sanjib Dhungel in association with Kyushu University, japan found high urinary salt (sodium) exceretion in people of Kotyang which indicated high salt intake. 11 However, their blood pressure was relatively lower, probably due to their higher degree seen in the Dharan hypertension study where the labourers had less hypertension despite higher salt consumption. 5 Dr. Gopal Acharya and Japanese colleagues went a step further and did genestic study. They found that it was because of an ACE I/D gene polymorpphism that despite eating about $11 \mathrm{gm}$ salt daily, the villagers studied had a lower pressure. 12

\section{Science vs. Salt industry debate}

Though most of the studies favour the hypothesis that increase salt intake leds to high lood pressure, there is a contradictory group of researchers that actually refute the association and claim that salt has been injudiciously blamed for various ill-effects including high blood pressure. 13-14 Those who argue against lowering sodium intake caution that the available evidence doesn't warrant a mandate to lower salt consumption for everyone. They argue that salt is a vital nutrient and limiting its consumption could have unforeseen implications upon the nervous system and insulin resistance. However, it must be kept in mind that these arguments are basically commercially motivated. For example, salt is a $\$ 340$ million per year industry in the United States; and the food industry depends heavily upon the ubiquitous white crystal. It is a cheap means of adding "flavour" to processed foods and extending shelf life. Plus, it makes us thirsty so we buy more beverages. Any official recommendations to downsize the amount of salt in the American diet would have farreaching, multimillion dollar consequences. Not surprisingly, for every study that confirms excess salt is a primary cause of hypertension, kidney disease and other evils, another expert or industry-aligned representative quickly appears to downplay the findings and suggested that restricting sodium for the overall population would have unhealthy, perhaps even dangerous effect. Needless to say, these contradictory health recommendations have confused consumers.

\section{How to avoid Salt to Reduce Blood Pressure:}

1. Avoid highly processed food which usually contains excessive salt: Regrettably, most of what we eat today is junk food such as chips, noodles and canned foods. They contain excess amount of salt. Consider for a moment, the idea of cutting back on the amount of salt in your diet. What's the first thing you'd do? If you glanced suspiciously at your saltshaker, you might be surprised to learn that the food we prepare at home accounts for only ablut 11 percent of the salt most of us consume inn a single day. Instead, the bulk of the salt we eat-anywhere from 75 percent to 80 percent-is added to processed foods. Pass on the salt at the dinner tale, and you still can consume more than the recommended daily amount by stopping at the fast-food joint for lunch. Even many of the 'traditional' food that we eat are also quite salty. Home-made processed pickels (achar), bhujiya and papad they all contain excessive salt and should be minimally consumed.

2. Read food labels carefully, particularly highly processed foods: Though most processed foods are labeled with the amount of salt that it contains, these labels are difficult to understand. The easiest way to avoid salt is to stick to a couple of rules: Avoid all foods that have more than $0.2 \mathrm{gm}$ of sodium per $100 \mathrm{gm}$. Examples: Cornflakes=1.1, Bread=0.5-1.2, Cheese $=0.6-1.4$. Ideally only eat foods containing less than 0.1 gm of sodium per $100 \mathrm{gm}$. There is a huge difference between the levels of sodium in fresh and processed foods. Examples include: Fresh Fruit $=0.0-0.01$, Vegetables $=0.0-0.02$, Fresh Meat $=0.05$, Fresh Fish $=0.05$.

3. Increase fruits and vegetables in your diet, and decrease alcohol consumption: Fruits and vegetables provide potassium that counteracts the blood pressure raising effect of the salt (sodium). They also supply anti-oxidants that protect the body against harmful radicals. Reducing alcohol not only directly helps in reducing blood pressure; it also cuts down the extra salt consumed with 'snacks'.

4. Cut back salt intake gradually over a period of weeks or moths: Minimize salt to cooking or at the table do not put the salt shaker on the table. You may find fairly quickly that your sense of taste adjusts so that you no longer like the taste of salt. Try to use fresh, unprocessed food e.g. vegetables, fruit, fish, chicken and meat, which all contain only very small amounts of salt. To enhance the flavour of food, use herbs and spices, flavoured vinegars or lemon juice, instead of salt. Caraway seeds, Pepper, Garlic, Parsley, Sesame, Thyme, are all possible alternate flavours which can be tried.

\section{How to avoid Salt to Reduce Blood Pressure}

The average daily salt intake in worldwide is about 9-12 grams per person whereas the World Health Organization recommends not more than 1 teaspoonful of salt (5-6 grams) per day. Some of the ways that can help cut down salt intake, as well as the risk for high blood pressure are given in the box.

\section{REFERENCES}

1. Kearney PM, Whelton M, Reynolds K, Muntner P, Whelton PK, He J, Global burden of hypertension: analysis of the worldwide data Lancet 2005;365:217-23.

2. Pandey MR, Hypertension in Nepal. Biblthea Cardio 1987;42:68-76.

3. Pandey MR, Dhungel S. Prevalence of hypertension in an urban community of Nepal. Journal of Nepal Medical Association 1983;21:1-5.

4. Pandey MR, Upadhyay LR, Dhungel S. prevalence of hypertension in a rural community in Nepal. Indian Heart J 1981;33:284-9.

5. Vaidya A, Pokharel PK, Karki P, Nagesh S. Exploring the iceberg of hypertension: A community based study in an Eastern Nepal town. KUMJ 2007,5(3):349-359.

6. Ghimire PK, Prevalence of hypertension in THe Surkhet valley of Western Nepal. \{Unpublished report\}.

7. Conlin PR, Chow D, Miler ER 3rd, Svetkey LP, Lin PH, Harsha DW, wt al. The effect of dietary patterns on blood 
pressure control in hypertensive patients: results from the Dietary Approaches to Stop Hypertension (DASH) trial. Am J Hypertens. 2000 Sep;13(9):949-55.

8. He F J, Marrero N M, MacGregor G A. Salt Intake is Related to Soft Drink Consumption in Children and Adolescents: A Link to Obesity? Hypertension 2008;51;629-634.

9. Pollard TM, Ward GA, Thornley J, Wooster G, Wooster J, Panter-Brick C, Modernisation and children's blood pressure: On and off the tourist trail in Nepal. Am J Hum Biol. 2000 Jul;12(4):478-486.

10. Stamler J. The INTERSALT Study: background, methods, findings, and implications, American Journal of Clinical Nutrition, Vol 65, 626S-642S.
11. Kawasaki T, Itoh K, Uezono K, , ogata M, Dhungel $\mathrm{S}$, Sharma $\mathrm{S}$, et al. Investigation of high salt intake in a Nepalese population with low blood pressure. J Hum Hypertens. 1993 Apr;7(2):131-40.

12. S Umemura, T Kawasaki, T Ishigami, T Fujita, K Hibi, , Acharya G P. Angiotensin-converting enzyme gene polymorphism in Nepal. Journal of Human Hypertension 1998;12:527-31.

13. Alderman $M N$, Cohen H, Madhavan S. Dietary sodium intake and mortality: the National Health and Nutrition Examination Survey (NHANESI). Lancet 1998;351:78185.

14. Whalley H. Salt and Hypertension: consensus or controversy? Lancet 1997;350:1686. 